Arq. Bras. Med. Vet. Zootec., v.64, n.3, p.615-622, 2012

\title{
Lithothamnium calcareum no tratamento de osteotomia experimental em coelhos (Oryctolagus cuniculus)
}

\author{
[Lithothamnium calcareum in the treatment of experimental osteotomy \\ in rabbits (Oryctolagus cuniculus)] \\ N.S. Ucrós ${ }^{1}$, W.M. Ferreira ${ }^{2}$, R.C.S. Torres ${ }^{2}$, N.F. Borges ${ }^{1}$, S.S. Silveira ${ }^{3}$, C.M.F. Rezende ${ }^{2}$ \\ ${ }^{1}$ Aluna de pós-graduação - Escola de Veterinária - Universidade Federal de Minas Gerais - Belo Horizonte, MG \\ ${ }^{2}$ Escola de Veterinária - Universidade Federal de Minas Gerais - Belo Horizonte, MG \\ ${ }^{3}$ Aluna de graduação - Escola de Veterinária - Universidade Federal de Minas Gerais - Belo Horizonte, MG
}

\section{RESUMO}

Avaliaram-se os efeitos da suplementação com Lithothamnium calcareum na consolidação de osteotomia experimental em coelhos, por meio de exames radiográfico e histológico. Utilizaram-se 10 coelhos machos da raça Nova Zelândia, de quatro a cinco meses de idade, com massa corporal média de $2,5 \mathrm{~kg}$, os quais foram submetidos à osteotomia do terço médio da tíbia direita e à fixação interna com dois pinos intramedulares. Os coelhos foram distribuídos aleatoriamente em dois grupos experimentais (A e B) com cinco animais cada. O grupo A recebeu diariamente dieta contendo $0,75 \%$ de L. calcareum, e o grupo B constituiu o controle sem tratamento adicional à fixação da osteotomia. A evolução clínica ocorreu sem intercorrências. As radiografias foram realizadas antes do estudo e em intervalos de 15 dias até o final do experimento, e a histologia foi realizada aos 60 dias. As avaliações radiográficas permitiram acompanhar a evolução do processo de consolidação que ocorreu em todos os casos. Histologicamente, verificou-se consolidação completa em todos os animais do grupo B (controle) e em $75 \%$ do grupo A. Dos resultados pode-se concluir que, embora tenha ocorrido a consolidação clínica e a radiográfica aos 60 dias em todos os casos, histologicamente o grupo-controle (B) foi melhor, mostrando que o organismo sadio não necessita de estímulo para o processo de reparação óssea. Novas pesquisas devem ser realizadas para avaliar o efeito da suplementação mineral em animais portadores de deficiências nutricionais.

Palavras-chave: coelho, Lithothamnium calcareum, osteotomia

\begin{abstract}
The purpose of this work was to evaluate Lithothamnium calcareum suplementation in the consolidation of experimental osteotomy in rabbits, through radiographic and histology examinations. Ten male New Zealand white rabbits, 4-5 months of age with an average body mass of 2.5kg, had surgically induced mid-tibial osteotomies, fixed with two intramedullary pins. The animals were randomly divided into two experimental groups (A and B). Group A received a diet containing $0.75 \%$ of $\mathrm{L}$. calcareum, and group B served as control without further treatment of the osteotomy fixation. Radiographs were done every 15 days until the end of the experiment and histology was performed at day 60. Radiographs show consolidation in all cases. Histologically there was bone consolidation in all animals in group $B$ (control), and $75 \%$ in group A. From the results we can conclude that, although there was clinical and radiographic bone consolidation in all cases after 60 days, the control group proved to be better histologically, showing that a healthy organism needs no aid to repair bone. Further research should be conducted to assess the effects of mineral supplementation on animals with nutritional deficiencies.
\end{abstract}

Keywords: rabbit, Lithothamnium calcareum, osteotomy

Recebido em 4 de março de 2011

Aceito em 13 de abril de 2012

E-mail: naty.ufmg@gmail.com 


\section{INTRODUÇÃO}

O osso, um tecido conjuntivo duro especializado, tem importantes funções estruturais e metabólicas e possui grande capacidade de regeneração (Doblaré et al., 2004). O tecido ósseo, provido de força e rigidez, tem elasticidade limitada e, quando lesado, inicia-se uma série de reações que, sob condições normais, têm o potencial para restaurar a arquitetura e as propriedades mecânicas do tecido (Schelling, 1991; Webb e Tricker, 2000; Hungria, 2007; Schindeler et al., 2008). Esse complexo processo, que envolve a interação de diversos mecanismos, está sujeito a variações e pode ser dividido em diferentes fases sequenciais que compreendem: inflamação aguda, formação do hematoma, angiogênese, formação do calo, ossificação e remodelação (Webb e Tricker, 2000; Doblaré et al., 2004). A consolidação secundária ocorre na grande maioria das fraturas, onde existe micromovimento entre os fragmentos ósseos que são progressivamente estabilizados pela formação de calo (Schelling, 1991; Hungria, 2007). Os pinos intramedulares, um dos dispositivos de fixação óssea, reduzem, mas não impedem, o movimento dos fragmentos, o que estimula a invasão vascular e a formação do calo (Webb e Tricker, 2000). Segundo Richardson (2000), devido ao metabolismo acelerado do coelho, as fraturas apresentam calo ósseo por volta do $10^{\circ}$ dia após o trauma, sendo que a consolidação óssea completa, em fraturas sem complicações, ocorre geralmente em torno de seis semanas pós-trauma.

As descobertas relacionadas à biologia e ao metabolismo ósseos têm causado grande impacto na prática clínica ortopédica. De forma geral, o processo de consolidação óssea é uma combinação de processos anabólicos (formação óssea) e catabólicos (reabsorção óssea) (Doblaré et al., 2004; Schindeler et al., 2008). Como a resposta anabólica corresponde à formação de osso novo, a busca por métodos não invasivos que estimulem esta resposta adquire considerável importância e tem recebido destaque na literatura. Diferentes métodos terapêuticos têm sido pesquisados na tentativa de promover aceleração ou melhora do processo de regeneração óssea. Dentre eles encontram-se os nutracêuticos, usados como prevenção ou tratamento de doenças metabólicas (Andlauer e Furst, 2002; Doetsch et al., 2004). A nutrição tem uma intrínseca relação com a regeneração tecidual, uma vez que os nutrientes ingeridos somente serão utilizados para essas funções metabólicas, quando satisfeita a demanda para a manutenção do organismo (Morais e Burgos, 2007). Sabe-se que alguns minerais, como o $\mathrm{Ca}$ e o P, são essenciais para a saúde e a produtividade dos animais e possuem funções nutricionais $\mathrm{e}$ bioquímicas bem definidas. Além disso, são componentes estruturais dos tecidos ósseo e muscular (Mateos e Blas, 1998; Ilich e Kerstetter, 2000).

O Lithothamnium calcareum, uma alga marinha coralina vermelha, rica em elementos minerais, principalmente cálcio e magnésio, utilizada na nutrição animal, demonstrou ter efeitos variáveis (Dias, 2001). A sua utilização na alimentação animal foi avaliada em diferentes espécies, melhorando a saúde dos animais, o ciclo reprodutivo e a qualidade dos derivados como carne, leite e ovos (Melo et al., 2008; Euler, 2009). Uma das vantagens do seu uso como fonte de $\mathrm{Ca}$ na dieta, quando comparada com outras fontes, é sua alta solubilidade, fator diretamente relacionado à absorção intestinal e à biodisponibilidade (Airhart et al., 2002; Melo et al., 2006). Existem poucas pesquisas publicadas a respeito dos efeitos desta alga calcária sobre o tecido ósseo, porém já foram sugeridos efeitos anabólicos sobre os ossos, estimulando o crescimento (Assoumani, 1997), na consolidação de fratura (Palhares et al., 2008) e no tratamento de falha óssea (Teixeira, 2008). Pesquisas ainda devem ser conduzidas para se estudar o efeito do L. calcareum sobre a consolidação de fraturas.

O objetivo deste trabalho foi avaliar os efeitos da suplementação com Lithothamnium calcareum na consolidação de osteotomia experimental em coelhos, por meio de exames radiográfico e histológico.

\section{MATERIAL E MÉTODOS}

Este projeto foi aprovado pelo Comitê de Ética em Experimentação Animal (CETEA) da UFMG, sob o protocolo 01/2009. Foram utilizados 10 coelhos (Oryctolagus cuniculus) da raça Nova Zelândia, machos, de quatro a cinco meses de idade, com massa corporal média de 2,5kg. Durante um período de adaptação de 30 dias, todos os animais foram avaliados por exames clínico e laboratorial (hemograma) e 
submetidos a avaliação radiográfica de controle. Os 10 animais foram distribuídos uniforme e aleatoriamente em dois grupos experimentais (A, B) e mantidos em gaiolas individuais de arame galvanizado de $60 \times 60 \times 37 \mathrm{~cm}$, onde receberam ração formulada para o experimento e água à vontade. No pré-operatório, não foram realizados nem jejum hídrico nem alimentar (Richardson, 2000). Os coelhos receberam $30 \mathrm{mg} / \mathrm{kg}$ de cefalotina (Cefamox, Bristol-Meyers-Squibb) via intravenosa como antibiótico profilático, 30 minutos antes da cirurgia. A sedação foi feita com 20mg/kg de cloridrato de cetamina (Ketalar® 10\%, Pfizer, São Paulo) e $2,5 \mathrm{mg} / \mathrm{kg}$ de cloridrato de xilazina (Rompum® ${ }^{\circledR} \%$, Bayer SA) via intramuscular. Após a sedação, foi feita tricotomia ampla do membro pélvico direito (MPD) da região lombar até a articulação tibiotársica e anestesia epidural na região lombossacra, entre as vértebras L7 e S1, com $12,5 \mathrm{mg} / \mathrm{kg}$ de bupivacaina (Neocaina ${ }^{\circledR} 5 \%$, Cristália). A anestesia foi feita com propofol (Propofol, Cristália) via intravenosa, segundo a necessidade. Durante todo o período anestésico, foram monitoradas as frequências cardíaca e respiratória. Fluidoterapia de apoio foi feita com solução de cloreto de sódio a $0,9 \%$.

Com o animal em decúbito lateral direito, foi realizada antissepsia com solução de iodopolivinilpirrolidona (PVPI) degermante seguida por solução alcoólica de iodo a $2 \%$ desde a articulação coxofemoral até a articulação tibiotársica. Seguiu-se a colocação dos panos de campo. Foi realizada a abordagem da tíbia mediante incisão cutânea na superfície medial, de aproximadamente $2,0 \mathrm{~cm}$ de extensão. O tecido subcutâneo e a fáscia crural foram afastados e a tíbia foi exposta. Com uma serra oscilatória acoplada à furadeira pneumática (Furadeira pneumática 3M® 0-1100rpm) e sob irrigação constante com solução fisiológica a $0,9 \%$, foi realizada a osteotomia transversal do terço médio da tíbia. Seguiu-se a osteossíntese com a inserção normógrada de dois pinos intramedulares, utilizando-se perfurador manual. O diâmetro dos pinos foi determinado conforme o calibre do canal medular, variando segundo o diâmetro das tíbias. Após a coaptação dos fragmentos ósseos mediante utilização de duas pinças autocentrantes, os pinos foram introduzidos no ponto médio entre a crista da tíbia e o ligamento colateral medial, orientados no eixo longitudinal até atingirem um ponto de maior resistência no terço distal da tíbia. Verificou-se a estabilidade do foco da osteotomia mediante discreta rotação externa e interna do membro. Uma vez estável, os pinos foram dobrados e cortados cerca de $0,5 \mathrm{~cm}$ do osso com um alicate articulado para cortar pinos.

A fáscia crural e o tecido subcutâneo foram aproximados com fio absorvível de ácido poliglicólico 5-0 (Safil®, São Paulo) em padrão contínuo simples. A dermorrafia foi realizada por pontos separados simples com náilon monofilamentar 5-0 (Ethicon). Foram obtidas radiografias do MPD nas projeções craniocaudal (CrCa) e mediolateral (ML) de todos os animais, antes da cirurgia (controle), imediatamente após e nos tempos $15,30,45$ e 60 dias de pósoperatório. Os animais não receberam nenhum tipo de sedação para este procedimento, sendo utilizada apenas a contenção manual. Foram usados equipamento radiográfico de $500 \mathrm{~mA}$ e filmes para raio-X tamanho $24 \times 30$. Foi feita avaliação duplo-cega das radiografias por três avaliadores distintos que desconheciam o tempo de realização do exame e o grupo experimental de cada animal. Para isto, foi colocado em cada radiografia um número aleatório (01-50), e com o auxílio de um escore, foi qualificada a evolução do processo de consolidação óssea. Para a análise, utilizou-se a média dos valores registrados. Reação periosteal (RP), formação de calo ósseo (CO), formação de ponte óssea (PO), presença de linha de osteotomia (LO) e remodelação (R) foram os parâmetros semiquantitativos usados para a avaliação.

Foram formulados dois tipos de dieta experimental: uma dieta-controle ou de referência, formulada segundo as recomendações de Mateos e Blas (1998) a fim de atender as exigências nutricionais de coelhos nesta faixa etária, e uma dieta com nível de inclusão de $0,75 \%$ de farinha de algas marinhas (Lithothamnium calcareum, Suminal® Algarea Mineração) em substituição à bentonita da dieta-controle. Os níveis de todos os demais nutrientes (carboidratos, proteínas, gordura e micronutrientes) foram mantidos iguais para as duas dietas. Os ingredientes utilizados para a fabricação de cada dieta foram rigorosamente pesados, misturados e peletizados, com grânulos de $12-15 \mathrm{~mm}$ de comprimento por $4-5 \mathrm{~mm}$ de diâmetro. As dietas foram disponibilizadas todos os dias no mesmo horário, segundo o cálculo do 
consumo de $5 \%$ do peso do animal. Porém, foram oferecidos $25 \%$ além do calculado, para garantir a disponibilidade constante de alimento.

Os coelhos foram distribuídos aleatoriamente em dois grupos experimentais (A, B), com cinco animais cada. Os animais do grupo A receberam a dieta contendo o L. calcareum, e os animais do grupo B constituíram o grupo-controle e não receberam nenhum tratamento adicional à fixação da osteotomia. Aos 60 dias foi realizada eutanásia dos animais mediante injeção intravenosa de sobredose anestésica, utilizandose $90 \mathrm{mg} / \mathrm{kg}$ de tiopental sódico (Thiopentax $®$, Cristália), após sedação com $5 \mathrm{mg} / \mathrm{kg}$ de cloridrato de xilazina IV lenta. A tíbia do membro direito foi retirada por meio da desarticulação das articulações fêmoro-tíbiopatelar e tibiometatársica. A seguir, foi realizada dissecção cuidadosa do osso, retirando-se todos os tecidos moles, com o cuidado para não interferir no calo ósseo. As peças foram identificadas, fotografadas e colocadas em recipientes adequados com solução de formalina neutra $10 \%$ em tampão fosfato por 30 dias. Fragmentos ósseos de $4 \mathrm{~cm}$ de diâmetro, conservados em formalina neutra $10 \%$ em tampão fosfato durante 30 dias, foram envolvidos em gaze e identificados para descalcificação em solução de ácido fórmico 24\%, tamponado com citrato de sódio, $\mathrm{pH}$ 4.5. As 10 amostras foram colocadas no mesmo recipiente e imersas em solução descalcificadora. A solução foi trocada a cada três dias até a comprovação radiográfica de completa descalcificação do tecido. Após a descalcificação, as amostras foram processadas segundo procedimento padrão. Cortes longitudinais de $5 \mu \mathrm{m}$ de espessura foram corados com hematoxilina-eosina (HE) para observação por microscopia óptica de luz. Avaliação histológica das amostras foi feita por um avaliador que desconhecia a distribuição dos tratamentos. Para isto, as lâminas foram marcadas aleatoriamente com um número (0110) e foi qualificada a consolidação óssea em termos de presença de calo ósseo e união óssea.

Para a análise estatística, foi utilizado um delineamento inteiramente casualizado (DIC) em parcelas subdivididas, com dois tratamentos e cinco repetições cada, utilizando-se o programa SAS. Para cada variável foram determinados a média e o desvio-padrão, e realizada análise de variância (ANAVA) com níveis de significância de $5 \%(\mathrm{p}<0,05)$. Os parâmetros avaliados nas radiografias (reação periosteal, formação de calo ósseo, formação de ponte óssea, presença de linha de fratura e remodelação) foram analisados por testes de Friedman para comparação entre os tempos, e de Kruskal-Wallis para comparação entre os tratamentos. A avaliação histológica foi analisada pelo teste Kruskal-Wallis para comparação entre tratamentos.

\section{RESULTADOS E DISCUSSÃO}

\begin{abstract}
A suplementação com o Lithothamnium calcareum foi de fácil manejo mediante sua inclusão na ração, como descrito na literatura (Mateos e Blas, 1998; Dias, 2001; Melo et al., 2008). A dose utilizada já é conhecida (Euler, 2009) e não traz prejuízo à saúde.
\end{abstract}

Os coelhos mostraram-se dóceis e permitiram a realização das radiografias apenas com contenção manual. Os exames radiográficos realizados em diferentes tempos durante o pósoperatório possibilitaram acompanhar o processo de consolidação da osteotomia (Fig. 1). Verificou-se em todos os animais, nas projeções CrCa e ML no pós-operatório imediato, o correto posicionamento dos pinos na tíbia e a coaptação dos fragmentos ósseos (Fig. 1), com redução satisfatória da osteotomia em todos os animais. 

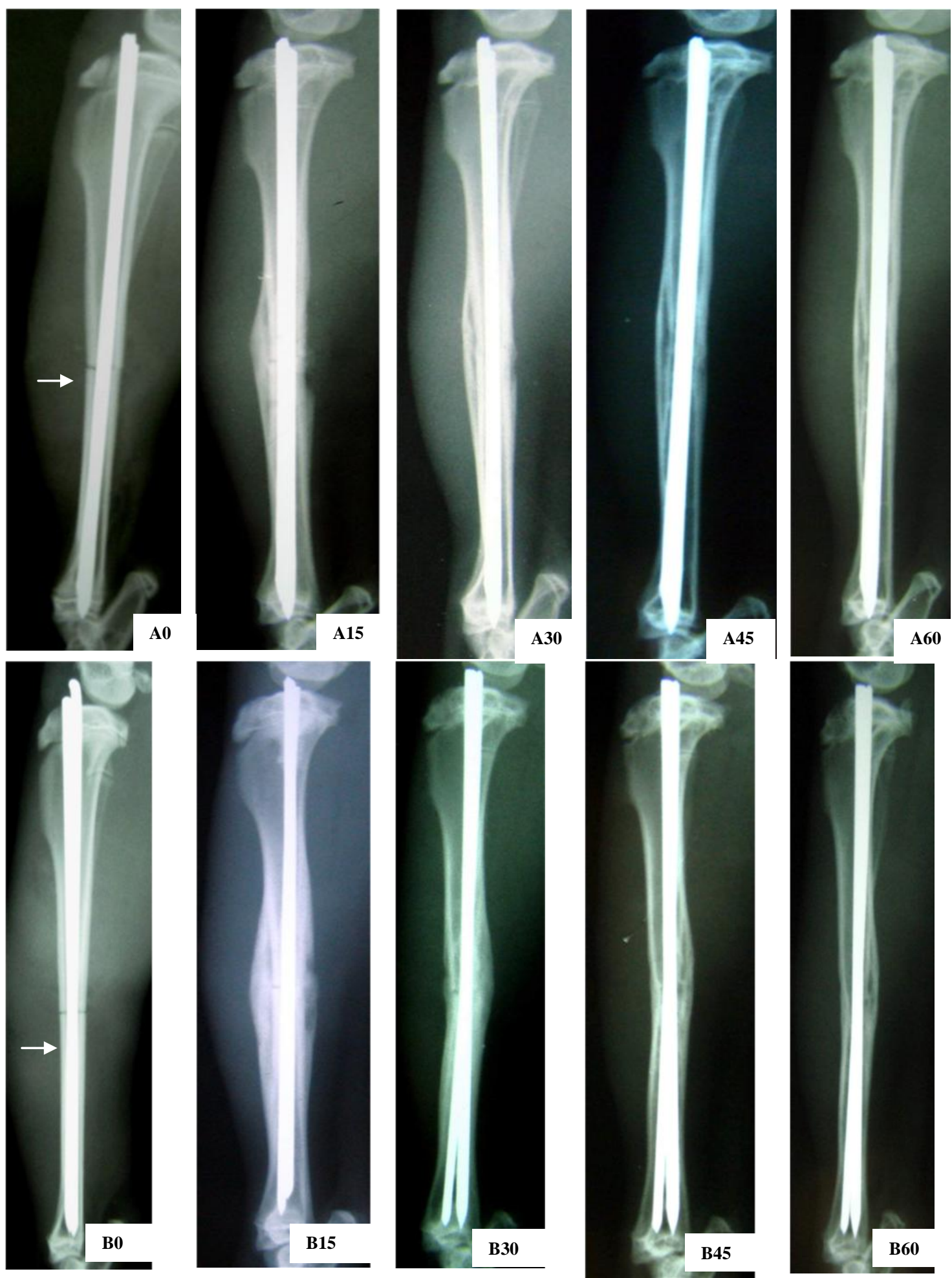

Figura 1. Imagem fotográfica das radiografias. Grupos experimentais A (L. calcareum), B (controle), nos diferentes tempos de avaliação $(0,15,30,45,60$ dias de pós-operatório). A0, B0: pós-operatório imediato: observam-se o posicionamento dos pinos e a linha de osteotomia (seta branca). A15, B15, A30, B30, A45, B45, A60, B60: observam-se evolução da consolidação óssea, redução progressiva do calo ósseo, desaparecimento da linha de osteotomia e remodelação. 
Diferenças estatisticamente significativas entre os tempos de avaliação foram encontradas para todos os parâmetros considerados $(\mathrm{P}<0,05)$, mas não entre os tratamentos $(\mathrm{P}>0,05)$. Nas Tab. $1 \mathrm{e}$ 2 , apresenta-se a mediana dos cinco parâmetros analisados, comparando-se os diferentes tempos de avaliação (Tab. 1) e os tratamentos (Tab. 2). As diferenças observadas entre os tempos mostram a evolução do processo de reparação tecidual, como esperado (Schelling, 1991; Webb e Tricker, 2000; Doblaré et al., 2004; Hungria, 2007; Schindeler et al., 2008). A linha de osteotomia estava presente aos 15 dias do pósoperatório, tornando-se menos definida aos 30 e 45 dias, com presença parcial (uma cortical) aos 60 dias em $20 \%$ (1) dos animais do grupo A ( $L$. calcareum). Em todos os animais observou-se reação periosteal 15 dias após a cirurgia, que foi diminuindo gradativamente até os 60 dias. Os animais do grupo A apresentaram, em média, menor reação periosteal que aqueles do grupocontrole em todos os tempos avaliados (Tab. 2). De forma semelhante, observou-se formação de calo ósseo aos 15 dias do pós-operatório, o qual se mostrou, em média, discretamente menor nos animais do grupo A (Tab. 2). A partir dos 30 dias, o calo ósseo foi reduzindo gradativamente, sendo que, aos 60 dias, ainda era observado calo discreto. Apesar de o tamanho do calo ter sido inicialmente menor nos animais do grupo A, observou-se que, a partir dos 45 dias, era semelhante ao do grupo-controle (B). Os dispositivos de fixação de fraturas, como pinos intramedulares, permitem micromovimento dos fragmentos ósseos, estimulando a formação de calo ósseo (Schindeler et al., 2008). Discretos sinais de remodelação foram observados radiograficamente no calo ósseo em $60 \%$ dos animais aos 15 dias do pós-operatório. Este processo foi evoluindo à medida que a consolidação ocorria. Aos 60 dias, foi observado um avançado processo de remodelação, com visibilização da restauração do canal medular em $40 \%$ (2) dos animais do grupo A e em $20 \%$ (1) dos animais do grupo B, sugestivo da fase final do processo de remodelação (Schelling, 1991). Na maioria dos coelhos (7), esta observação não foi possível devido à presença dos pinos no canal medular. Esta evolução está dentro do esperado para consolidação de fraturas em coelhos (Richardson, 2000).

Tabela 1. Valores das medianas dos parâmetros avaliados na radiografia. Reação periosteal, formação de ponte óssea, formação de calo ósseo, presença de linha de osteotomia e remodelação, antes da cirurgía, aos $15,30,45$ e 60 dias

\begin{tabular}{cccccc}
\hline \multirow{2}{*}{$\begin{array}{c}\text { Tempo } \\
\text { (dias) }\end{array}$} & RP & PO & CO & LO & R \\
\cline { 2 - 5 } T0 & $0,000 \mathrm{a}$ & $0,000 \mathrm{a}$ & $0,000 \mathrm{a}$ & $0,000 \mathrm{a}$ & $0,000 \mathrm{a}$ \\
T15 & $1,667 \mathrm{~b}$ & $0,667 \mathrm{ab}$ & $1,667 \mathrm{~b}$ & $0,667 \mathrm{ab}$ & $0,333 \mathrm{ab}$ \\
T30 & $1,000 \mathrm{c}$ & $2,167 \mathrm{bc}$ & $2,000 \mathrm{~b}$ & $1,667 \mathrm{bc}$ & $1,333 \mathrm{bc}$ \\
T45 & $1,000 \mathrm{c}$ & $2,667 \mathrm{c}$ & $1,500 \mathrm{~b}$ & $2,500 \mathrm{~cd}$ & $2,333 \mathrm{c}$ \\
T60 & $0,000 \mathrm{a}$ & $2,667 \mathrm{c}$ & $1,667 \mathrm{~b}$ & $2,833 \mathrm{~d}$ & $2,500 \mathrm{c}$ \\
\hline
\end{tabular}

Medianas seguidas de letras distintas nas colunas diferem pelo teste de Friedman $(p<0,05)$.

RP- reação periosteal; PO- ponte óssea; CO- calo ósseo; LO- linha de osteotomia; R-remodelação;

TO- antes da cirurgia; T15- 15 dias; T30- 30 dias; T45- 45 dias; T60- 60 dias.

Tabela 2. Medianas dos parâmetros avaliados na radiografia. Reação periosteal, formação de ponte óssea, formação de calo ósseo, presença de linha de osteotomia e remodelação, avaliados nos diferentes tratamentos: A (L. calcareum), (B) controle

\begin{tabular}{cccccc}
\hline \multirow{2}{*}{ Tratamento } & \multicolumn{5}{c}{ Parâmetro } \\
\cline { 2 - 6 } & RP & PO & CO & LO & R \\
\hline A & $1,000 \mathrm{a}$ & $2,333 \mathrm{a}$ & $1,333 \mathrm{a}$ & $2,333 \mathrm{a}$ & $1,667 \mathrm{a}$ \\
$\mathrm{B}$ & $1,333 \mathrm{a}$ & $2,000 \mathrm{a}$ & $1,667 \mathrm{a}$ & $1,667 \mathrm{a}$ & $1,000 \mathrm{a}$ \\
\hline
\end{tabular}

Medianas seguidas de letras distintas nas colunas diferem pelo teste de Kruskal-Wallis $(\mathrm{p}<0,05)$.

RP-reação periosteal; PO- ponte óssea; CO-calo ósseo; LO- linha de osteotomia; R- remodelação

Os resultados observados radiograficamente sugerem uma evolução do processo de consolidação em ambos os grupos. Esperava-se, entretanto, algum efeito adicional da suplementação com o L. calcareum face a sua maior biodisponibilidade dos macro e 
microminerais presentes na alga (Airhart et al., 2002; Melo et al., 2006), mas isto não foi observado. Efeitos positivos da suplementação com o L. calcareum foram observados por Assoumani (1997), em experimento com ratos, o qual relatou que a farinha de algas apresentou vantagens em relação ao calcário no crescimento do fêmur. Também foram observados efeitos positivos na consolidação de defeito ósseo em cães (Teixeira, 2008) e de fratura em equino (Palhares et al., 2008). Segundo Dias (2001), o efeito do $L$. calcareum na recuperação de fraturas é inerente às características do produto, tais como altas concentrações de cálcio e nutrientes catalisadores do metabolismo. No entanto, neste estudo, a avaliação histológica realizada aos 60 dias do pós-operatório mostrou melhor união óssea nos animais do grupo-controle (Tab. 3). Na avaliação das amostras, observou-se que todas apresentaram consolidação da osteotomia, presença de ósteons secundários e primários, túneis vasculares com presença de osteoclastos nas áreas de remodelação ativa e discreto calo ósseo no endósteo ou no periósteo, compatíveis com processo normal de consolidação óssea (Schelling, 1991; Hungria, 2007; Schindeler et
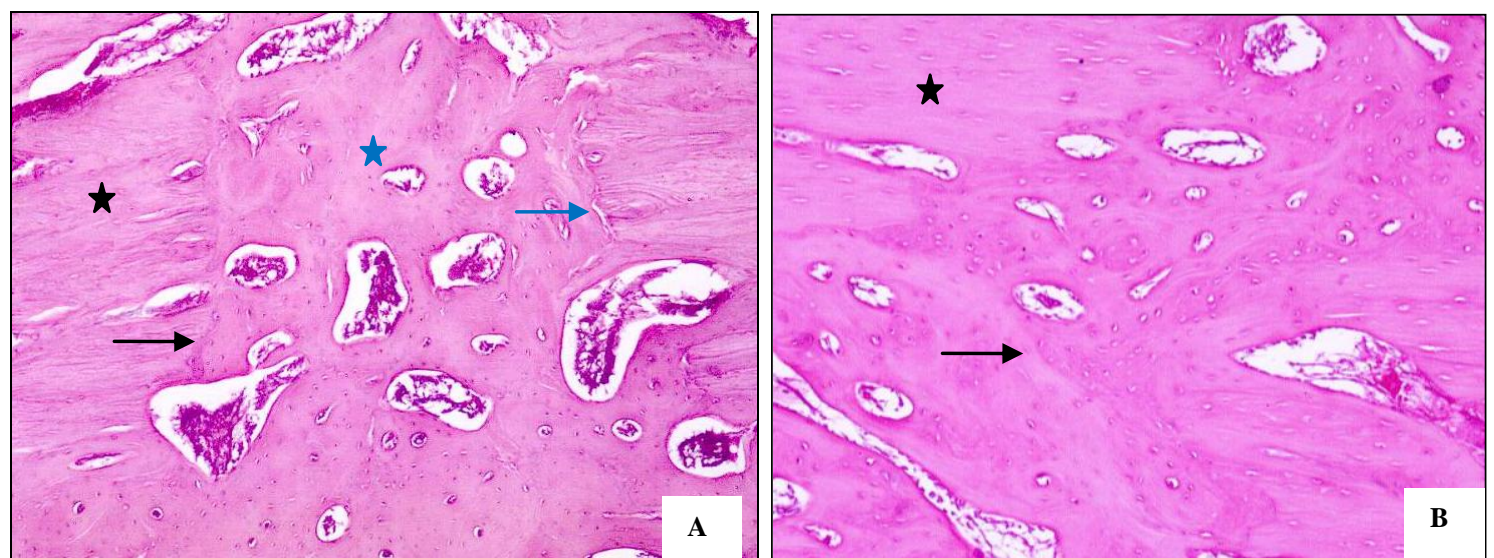

Figura 2. Microfotografia de osso cortical (corte longitudinal), do grupo suplementado com $L$. calcareum (A) e do grupo-controle (B) (x4). União óssea (seta preta), linha de osteotomia (seta azul), osso antigo (estrela preta) e osso novo (estrela azul).

Diante da escassa informação publicada sobre este assunto, mais pesquisas precisam ser desenvolvidas para se conhecer a melhor forma de utilização da farinha de algas marinhas, Liththamnium calcareum, definindo seu possível potencial anabólico. Acredita-se que a utilização de modelos animais com deficiências nutricionais poderia comprovar a ação benéfica do produto, pois resultados positivos da al., 2008) (Fig. 2). Entretanto, diferenças não significativas (Tab. 3) foram observadas na avaliação histológica $(\mathrm{P}>0,05)$. Os animais do grupo suplementado com o L. calcareum (A) tiveram, em média, menor formação de calo ósseo $(\mathrm{CO})$ do que os animais do grupo-controle (B). Todavia, observou-se que $60 \%$ (3) dos animais do grupo A (L. calcareum) tiveram união óssea (UO) completa e $40 \%$ (2) apresentaram fendas discretas da linha de osteotomia com sinais de remodelação ativa. Em contraste, todos os animais (5) do grupo-controle tiveram UO completa (Tab. 3). Portanto, do ponto de vista histológico, não houve benefício com a suplementação com L. Calcareum.

Tabela 3. Valores das medianas da avaliação histológica nos diferentes tratamentos. Presença de calo ósseo, união óssea

\begin{tabular}{ccc}
\hline Tratamento & $\mathrm{CO}$ & $\mathrm{UO}$ \\
\hline $\mathrm{A}$ & $0,00 \mathrm{a}$ & $2,33 \mathrm{a}$ \\
$\mathrm{B}$ & $2,00 \mathrm{a}$ & $3,00 \mathrm{a}$ \\
\hline
\end{tabular}

Medianas seguidas de letras distintas diferem pelo teste de Kruskal-Wallis ( $<<0,05)$. CO- calo ósseo; UO- união óssea. 
ser beneficiados pelas qualidades de solubilidade e biodisponibilidade do L. calcareum.

\section{CONCLUSÕES}

A suplementação com inclusão de $0,75 \%$ de Lithothamnium calcareum na dieta não apresenta vantagens na consolidação de osteotomia experimental em coelhos. A ausência de diferença estatística entre os tratamentos sugere que todos foram favoráveis, levando à conclusão de que o organismo sadio não necessita de fontes suplementares para a consolidação óssea.

\section{AGRADECIMENTOS}

Os autores agradecem à FAPEMIG pelo apoio, ao $\mathrm{CNPq}$ pela bolsa de estudo de mestrado, à Escola de Veterinária, à Fazenda Experimental Professor Hélio Barbosa e ao Laboratório de Metabolismo Animal da Escola de Veterinária da Universidade Federal de Minas Gerais pelo suporte necessário para completar o presente estudo.

\section{REFERÊNCIAS}

AIRHART, J.C.; TAYLOR, S.J.; PURSER, K.W. et al. The bioavailability in chicks of calcium in a product derived from calcified seaweed (Marigro). In: The Southern Poultry Science Society, 23rd Annual Meeting and The Southern Conference on Avian Diseases, 43rd Annual Meeting. S32, 2002, p.118.

ANDLAUER, W.; FURST, P. Nutraceuticals: a piece of history, present status and outlook. Food Res. Inter. v. 35, p.171-176, 2002.

ASSOUMANI, M.B. Aquamin, a natural calcium supplement derived from seaweed. Agro-food-Industry Hi Tech., v.9/10, p.46-47, 1997.

DIAS, G.T.M. Granulados Bioclásticos - Algas Calcárias. Braz. J. Geoph., v.18, p.301-318, 2001.

DOBLARÉ, M.; GARCÍA, J.M.; GÓMEZ, M.J. Modelling bone tissue fracture and healing: a review. Eng. Fract. Mech., v.71, p.1809-1840, 2004.

DOETSCH, A.M.; FABER, J.; LYNNERUP, N. et al. The effect of calcium and vitamin D3 supplementation on the healing of the proximal humerus fracture: A randomized placebo-controlled study. Calcif. Tissue Int., v.75, p.183-188, 2004.
EULER, A.C.C. Utilização digestiva, metodologias de avaliação in vitro de dietas e caracterização da microbiota cecal em coelhos suplementados com Lithothamnium. 2009. 78f. Tese (Doutorado em Zootecnia) - Escola de Veterinária, Universidade Federal de Minas Gerais, Belo Horizonte.

HUNGRIA, J.S. Consolidação Óssea. In: COHEN, M.; MATTAR Jr., R.; GARCIA, R.J. Tratado de ortopedia. São Paulo: Roca, 2007. p.623-626.

ILICH, J.Z.; KERSTETTER, J.E. Nutrition in Bone Health Revisited: A Story Beyond Calcium. Am. J. Clin. Nutr., v.19, p.715-737, 2000.

MATEOS, G.G.; BLAS, J.C. Minerals, Vitamins and Additives. In: BLAS, C.; WISEMAN, J. The nutrition of the rabbit. Cambridge:CABI Publishing., 1998. p.145-175.

MELO, T.V.; FERREIRA, R.A.; CARNEIRO, J.B.A. et al. Rendimiento de codornices japonesas utilizando harina de algas marinas y fosfato monoamónico. Arch. Zootec., v.57, p.381-384, 2008.

MELO, T.V.; MENDONÇA, P.P.; MOURA, A.M.A. et al. Solubilidad in vitro de algunas fuentes de calcio utilizadas en alimentación animal. Arch. Zootec., v.55, p.297-300, 2006.

MORAIS, G.Q.; BURGOS, M.G.P.A. Impactos dos nutrientes na saúde óssea. Rev. Bras. Ortop., v.42, p.189-194, 2007.

PALHARES, M.C.; MELO, U.P.; FERREIRA, C. et al. Tratamento conservativo de fratura ulnar em equino: relato de caso. In: CONFERENCIA SULAMERICANA DE MEDICINA VETERINÁRIA, 8., 2008, Rio de Janeiro. Anais... Rio de Janeiro: Anclivepa-RJ, 2008.

RICHARDSON, V.C.G. Anesthesia and Surgery. In: Rabbits: health, husbandry and diseases.

Oxford: Blackwell Science, 2000. p.151-157.

SCHELLING, S.H. Secondary (classical) bone healing. Semin. Vet. Med. Surg. Small Animal, v.6, p.16-20, 1991.

SCHINDELER, A.; McDONALD, M.M.; BOKKO, P. et al. Bone remodeling during fracture repair: The cellular picture. Semin. Cell \& Develop. Biol., v.19, p.459-466, 2008.

TEIXEIRA, R.G. Avaliação da farinha de algas marinhas (Lithothamnium calcareum) como suplemento mineral na cicatrização óssea de autoenxerto cortical em cães. 2008. 65f. Dissertação (Mestrado em Medicina Veterinária) - Escola de Medicina Veterinária da Universidade Federal da Bahia, Salvador.

WEBB, J.C.J.; TRICKER, J. Bone Biol. A review of fracture healing. Curr. Orthop. v.14, p.457-463, 2000. 